\title{
Management of acute diarrhoeal disease at Edendale Hospital: Are standard treatment guidelines followed?
}

\author{
K Reddy, ${ }^{1}$ MB BCh, B Pharm, FCPaed (SA); M E Patrick, ${ }^{1,2}$ MB ChB, DCH (SA), FCPaed (SA); \\ C R Stephen, ${ }^{3,4} \mathrm{MB} \mathrm{ChB}, \mathrm{DCH}(\mathrm{SA})$ \\ Department of Paediatrics and Child Health, Nelson R Mandela School of Medicine, Faculty of Health Sciences, University of KwaZulu-Natal, \\ Durban, South Africa \\ ${ }^{2}$ Greys Hospital, Pietermaritzburg Metropolitan Hospitals Complex, South Africa \\ ${ }^{3}$ Department of Paediatrics and Child Health, University of Cape Town, South Africa \\ ${ }^{4}$ Red Cross War Memorial Children's Hospital, Cape Town, South Africa
}

Corresponding author: KReddy (kershinee@yahoo.com)

\begin{abstract}
Background. Diarrhoeal disease (DD) is a major cause of childhood mortality in developing countries. In South Africa (SA), it ranks as one of the top five causes of under-5 mortality. Local and global guidelines on the management of acute DD are readily available. The Standard Treatment Guidelines (STGs) and Essential Drugs List for Hospital Level Paediatrics are a recognised standard of care for children in SA hospitals. However, children still die from this preventable disease.

Objective. To determine whether doctors adhered to standard treatment guidelines when treating children under 5 years of age presenting to Edendale Hospital in Pietermaritzburg, KwaZulu-Natal Province, with acute DD.

Methods. The study was a retrospective clinical audit of individual patient records.

Results. One hundred and thirty-five patient records were reviewed. Forty-seven percent had a correct nutritional assessment, $41 \%$ were correctly assessed for shock and $27 \%$ for dehydration. Appropriate investigations were undertaken in $12 \%$. Ninety-seven percent of patients had appropriate fluid plans prescribed. Zinc was prescribed in only $39 \%$ of patients, whereas $84 \%$ were appropriately not prescribed antibiotics and no patients received anti-diarrhoeal medication. In $90 \%$ of patients, the correct post-care patient referral was made, and $47 \%$ of caregivers were adequately advised about ongoing care of their children.

Conclusion. This study identifies substantial non-adherence to the SA STGs for the management of young children with acute DD.
\end{abstract}

The fourth Millennium Development Goal (MDG 4) committed participating countries to reduce the under-5 mortality rate (U5 MR) by two-thirds between 1990 and 2015. ${ }^{[1]}$ South Africa (SA) made insufficient progress of achieving the MDG 4 U5 MR target of 21 per 1000 live births by 2015. ${ }^{[2]}$ From 1990 to 2005, SA's rate of progress was lower than conflict-ridden countries such as Somalia, Iraq and the Democratic Republic of Congo. However, from the middle of the last decade, SA's U5 MR has declined significantly, and between 2006 and 2011, the annual rate of decline was the fourth fastest globally. ${ }^{[2]}$

Causes of death in children vary according to age. Globally, in 2011, the top five causes were preterm birth complications, diarrhoeal disease (DD), birth asphyxia, malaria and 'other' causes. ${ }^{[1]}$ In SA, during the neonatal period, preterm birth, birth asphyxia and infections contributed to the majority of early deaths. Outside the neonatal period, HIV/AIDS and childhood infections (especially diarrhoea and pneumonia) are the major causes of death and are also responsible for the majority of childhood morbidity in SA. ${ }^{[3]}$ According to the SA Child Healthcare Problem Identification Programme (PIP), for the period 2005 - 2009, DD was the second most important direct cause of death after acute respiratory infections. ${ }^{[4]}$ In SA, the incidence of DD decreased in the under- 5 age group from 286.4 cases per 1000 population in 1998 to 95.9 cases per 1000 population in $2011 .^{[5]}$ There was a decrease in DD incidence in all provinces. However, KwaZuluNatal (KZN) has shown a much smaller decrease when compared with other provinces. KZN's DD incidence was above the national average with 139.1 cases per 1000 population in $2011 .{ }^{[5]}$ Child PIP statistics from Edendale Hospital (EDH), a regional hospital in
KZN, between 2005 and 2013 showed that DD was the third most frequent cause of death in children under 5 years, but a decrease was noted in the overall under-5 in-hospital mortality rate (U5 IHMR). From January 2005 to July 2013, the U5 IHMR decreased from 8.4 to 2.5 deaths per 100 admissions.

In the 1978 declaration of Alma Ata, the availability of essential medicines was listed as one of the eight minimum requirements of primary healthcare. ${ }^{[6]}$ The concept of essential medicines is that the availability of a limited and select range of medicines would lead to better healthcare, better drug management, better use of financial resources, and therefore improved healthcare. Twenty-five years after the declaration, over 100 countries had national drug policies, 156 countries had national or provincial essential medicines lists and over 130 countries had developed national treatment guidelines to provide objective and unbiased guidance on rational use of medicines. ${ }^{[7]}$ National STGs were introduced in SA during 1996. ${ }^{[8]}$ At $\mathrm{EDH}$, an orientation programme is provided for all new doctors working in the paediatric department, irrespective of rank. This 2-week comprehensive training programme includes the assessment and management of DD and emphasises the overall importance of using guidelines in paediatrics. The objective of this study was to determine whether doctors in the EDH Paediatric Outpatient Department (POPD) followed the 2006 Standard Treatment Guidelines (STGs) and Essential Drugs List (EDL) for HospitalLevel Paediatrics when managing children with DD - the STGs and EDL for Hospital-Level Paediatrics 2006 were in use at the time of the study. A secondary objective was to assess differences in STG adherence between different ranks of attending doctor. 


\section{Methods}

This was a descriptive cross-sectional study, using a retrospective review of patient records to perform a clinical audit. The setting was the POPD at EDH in Pietermaritzburg, KZN, during two summer (January, February) and two winter (June, July) months in 2013. Patients aged 2 months to 5 years attending the Edendale POPD with acute DD were included in the study. Patients were identified using the POPD register for the respective study months. Relevant patient records were then obtained from the hospital's records department. The following were excluded: children with chronic DD, children with another coincident serious illness and children with dysentery. It was postulated that a review of $150-200$ patient records would provide sufficient data to describe doctors' adherence to the STGs. The first 100 patient records over the summer months and the first 100 patient records over the winter months were evaluated.

Two hundred patient records were retrieved, and 135 records met inclusion criteria. Sixtyfive were excluded (Fig. 1). Ten key actions in the management of children with DD were evaluated by the principal investigator. Apart from the nutritional assessment (which included the evaluation of moderate and severe malnutrition as current best practice according to the National Department of Health), all the actions were based on the 2006 STGs and EDL for Hospital-Level Paediatrics, namely:

1. Correct nutritional assessment

2. Correct assessment for shock

3. Correct assessment for dehydration

4. Appropriate investigations

5. Appropriate fluid management plans according to the child's dehydration severity assessment

6. Appropriate prescriptions, specifically:

a) prescription of zinc

b) non-prescription of antibiotics

c) non-prescription of anti-diarrhoeal mediation

7. Appropriate referral to the next place of care (home, oral rehydration corner or ward admission)

8. Adequate advice to caregivers regarding the diagnosis, severity of illness and ongoing care of their children.

For each of the ten actions, a compliance score was given, whereby compliant $=2$, partially compliant $=1$ or non-compliant $=0$.

A data collection tool was developed using a compliance scale (Appendix A). The tool also included demographic data (age, nutritional status, HIV status and rotavirus immunisation), the assessment of the child's fluid deficit (shock and dehydration) and the rank of attending doctor (intern, medical officer, registrar and paediatric specialist).
Data were analysed in Microsoft Excel (Microsoft Corp., USA). Simple descriptive statistics were used to assess adherence to STGs.

\section{Results \\ Patient demographics}

The median age of patients was 22 (range 2 - 60) months. The nutritional status was unknown in $53 \%$. Retrospective analysis of nutritional status in the unknown group showed that $89 \%$ had no acute malnutrition, $9 \%$ were classified as having moderate acute malnutrition and $3 \%$ were classified as having severe acute malnutrition. Seventy-eight percent were

HIV uninfected, and in $13 \%$ the HIV status was unknown. In $70 \%$ rotavirus vaccine had been given but in $22 \%$ this information was unknown. Over $40 \%$ of children were assessed as dehydrated and only $3 \%$ were assessed as shocked. Sixty-two percent of the patients were seen by interns and in $8 \%$ the doctor's rank was unknown (Table 1).

\section{Adherence to STGs}

Forty-seven percent of patients had a correct nutritional assessment. Forty-one percent of patients had a correct assessment for shock and $27 \%$ of patients had a correct assessment for dehydration. Twelve per cent had appropriate

Table 1. Demographic profile of patients with diarrhoeal disease $(N=135)$

\begin{tabular}{|c|c|}
\hline & $n(\%)^{*}$ \\
\hline \multicolumn{2}{|l|}{ Age (months) } \\
\hline Range & $2-60$ \\
\hline Median & 22 \\
\hline \multicolumn{2}{|l|}{ Nutrition } \\
\hline No acute malnutrition & $51(38)$ \\
\hline Moderate acute malnutrition & $7(5)$ \\
\hline Severe acute malnutrition & $6(4)$ \\
\hline Unknown & $71(53)$ \\
\hline \multicolumn{2}{|l|}{ HIV status } \\
\hline Infected & $4(3)$ \\
\hline Uninfected & $105(78)$ \\
\hline Uninfected and breastfed & $8(6)$ \\
\hline Unknown & $18(13)$ \\
\hline \multicolumn{2}{|l|}{ Rotavirus vaccine } \\
\hline Yes & $94(70)$ \\
\hline No & $11(8)$ \\
\hline Unknown & $30(22)$ \\
\hline \multicolumn{2}{|l|}{ Patient condition } \\
\hline \multicolumn{2}{|l|}{ Shocked } \\
\hline Yes & $4(3)$ \\
\hline No & $121(90)$ \\
\hline Unknown & $10(7)$ \\
\hline \multicolumn{2}{|l|}{ Dehydrated } \\
\hline Yes & $57(42)$ \\
\hline No & $67(50)$ \\
\hline Unknown & $11(8)$ \\
\hline \multicolumn{2}{|l|}{ Rank of attending doctor } \\
\hline Intern & $84(62)$ \\
\hline Medical officer & $21(16)$ \\
\hline Registrar & $19(14)$ \\
\hline Paediatric specialist & $0(0)$ \\
\hline Unknown & $11(8)$ \\
\hline
\end{tabular}


investigations undertaken. The most commonly omitted investigations were urine dipsticks and blood sugar finger prick. Ninety-seven percent of patients had fluid plans appropriate to their dehydration severity assessment. Thirty-nine percent of patients had zinc correctly prescribed. The correct non-prescription of antibiotics occurred in $84 \%$ of patients and no patients were prescribed anti-diarrhoeal medication, as outlined in the STGs. Ninety percent of patients received appropriate post-care referral. Patient records indicated that almost half of caregivers (47\%) were adequately advised on the diagnosis, severity of the illness and ongoing care of their children (Table 2).

\section{Discussion}

DD is a major cause of childhood mortality in developing countries. The annual mortality report released by Statistics SA for deaths occurring in 2013 listed intestinal infectious diseases as the leading cause of death in children under 5 years of age ${ }^{[9]}$ At EDH, where DD is ranked as the third most frequent cause of death in children under 5 years, this study found significant non-adherence to STGs for the management of DD by doctors in a setting of high DD prevalence.

There was poor adherence in six of ten key actions for managing children with DD, which is cause for concern. For these six steps, the average compliance by rank of doctor was $38 \%$ for interns, $36 \%$ for medical officers and $24 \%$ for registrars. It appears that the more senior the doctor, the lower the adherence.

\section{Nutrition}

Of the 135 patients, only $47 \%$ had a correct nutritional assessment, with low adherence rates by all ranks of doctor (Table 2). All children accessing healthcare should have a correct nutritional assessment, both because of the high prevalence of malnutrition in the population served, and because a child's nutrition status informs correct fluid management in DD.

\section{Shock and dehydration}

Only $41 \%$ of children had a correct assessment for shock and only $27 \%$ were correctly assessed for dehydration. This could reflect poor quality of care, poor quality of guidelines or poor documentation, or a combination of all three. Proper assessment of shock and dehydration is an important part of providing proper emergency care for children.

\section{Investigations}

Adherence to requesting appropriate investigations was low (12\%) for all ranks of doctor, mostly due to inadequate investigation.

\section{Fluid management}

Ninety-seven percent of patients appeared to have correct fluid management plans. However, this may have been an overestimate as doctors showed poor STG adherence for the assessment of shock and dehydration, making it difficult to match fluid plans with the actual clinical condition of the patient.

\section{Prescribing}

Zinc

While it is accepted that the use of zinc is beneficial in $\mathrm{DD},{ }^{[10]}$ only $39 \%$ of patients received zinc. In contrast to the overall trend by rank, registrars (53\%) prescribed zinc more often than interns (36\%).

\section{Antibiotics}

Sixteen percent of children had antibiotics prescribed, with no clear indication documented in the patient records, i.e. a condition other than DD. Antibiotic use is advocated in certain diarrhoeal conditions, e.g. dysentery, and also in some common medical conditions that may co-exist at the time of the diarrhoeal presentation. However, these patient records were specifically excluded from the study.

\section{Anti-diarrhoeal medication}

It was encouraging to find that no children were prescribed antidiarrhoeal medication. This may be because the use of anti-diarrhoeal medication is generally strongly discouraged in the management of $\mathrm{DD}$, by medical schools, in the clinical setting and in clinical guidelines.

\section{Place of further care}

Ninety percent of children were assigned to the correct place of further care. There was greater adherence among the medical officers (100\%) and interns (93\%), compared with the registrars (79\%).

\section{Caregiver advice/education}

Forty-seven percent of caregivers were adequately counselled. A possible reason for this low adherence is that attending doctors may not have recorded their counselling of the caregivers in the patient record. Nevertheless it cannot be assumed that the caregivers were counselled about danger signs on discharge or the use of ORS in DD if this was not documented.

\section{Rank of attending doctor}

The results showed non-adherence to treatment guidelines irrespective of the rank of attending doctor. Registrar adherence to

Table 2. Analysis of primary and secondary objectives: Adherence to STGs

\begin{tabular}{|c|c|c|c|c|c|}
\hline & \multicolumn{5}{|c|}{ Compliant, $n(\%)$} \\
\hline & \multirow{2}{*}{$\begin{array}{l}\text { Patients } \\
\text { Total }(N=135)\end{array}$} & \multicolumn{4}{|c|}{ Rank of attending doctor } \\
\hline & & Intern $(N=84)$ & $\begin{array}{l}\text { Medical } \\
\text { officer }(N=21)\end{array}$ & $\begin{array}{l}\text { Registrar } \\
(N=19)\end{array}$ & $\begin{array}{l}\text { Unknown } \\
(N=11)\end{array}$ \\
\hline Correct nutritional classification & $63(47)$ & $39(46)$ & $12(57)$ & $5(26)$ & $7(63)$ \\
\hline Correct shock assessment & $56(41)$ & $38(45)$ & $10(48)$ & $4(21)$ & $4(36)$ \\
\hline Correct dehydration assessment & $36(27)$ & $27(32)$ & $2(10)$ & $2(11)$ & $5(45)$ \\
\hline Appropriate investigations & $16(12)$ & $9(11)$ & $4(19)$ & $2(11)$ & $1(9)$ \\
\hline Appropriate fluid plan & $131(97)$ & $81(96)$ & $21(100)$ & $19(100)$ & $10(91)$ \\
\hline Appropriate zinc prescription & $52(39)$ & $30(36)$ & $9(43)$ & $10(53)$ & $3(27)$ \\
\hline Non-prescription of antibiotics & $113(84)$ & $72(86)$ & $15(71)$ & $17(89)$ & $9(82)$ \\
\hline Non-prescription of anti-diarrhoeals & $135(100)$ & $84(100)$ & $21(100)$ & $19(100)$ & $11(100)$ \\
\hline Appropriate referral to next place of care & $122(90)$ & $78(93)$ & $21(100)$ & $15(79)$ & $8(73)$ \\
\hline Adequate counselling provided & $64(47)$ & $48(57)$ & $8(38)$ & $4(21)$ & $4(36)$ \\
\hline
\end{tabular}


STGs was lower than interns for six of the ten actions, i.e. nutritional classification, shock assessment, dehydration assessment, use of investigations, further place of care and counselling of caregivers. Furthermore, registrars also scored lower than medical officers for five of the ten actions. This is a major concern as registrars are specialists-in-training and have an important role to play in supervising and teaching their junior colleagues, and in role modelling.

The study showed that guidelines were not being properly followed by doctors at EDH POPD. This may adversely affect the quality of care received by patients, the utilisation of resources, costs to the hospital and income for parents who may have to stay in hospital with their children.

It is not known from this study whether or not substantial nonadherence to DD guidelines directly impacts mortality. However, this possibility is also a cause for concern.

The study findings are surprising for a number of reasons. At medical schools, the pathophysiology and management of DD is taught in great detail through lectures and the use of prescribed texts. But focus on the management of DD according to the STGs in particular is often not included. Instead the focus is more on the use of Integrated Management of Childhood Illness (IMCI) guidelines for management of DD and other common conditions. In the IMCI guidelines, assessment of dehydration and fluid management is similar to that described in the STGs. In the authors' experience, the use of the STGs was first emphasised during internship and subsequent training years.

$\mathrm{EDH}$ is a typical KZN regional hospital providing primary and regional levels of care. It is possible that studies in other KZN hospitals may reveal similar findings of non-adherence to STGs.

Reasons given for non-adherence include lack of time due to high patient load, staff shortages, lack of supervision of junior doctors, increased pressure on senior doctors, poor documentation of findings in patient records and/or poor interpretation of clinical signs, all of which may have serious implications for the patient. Staff indifference to the use of guidelines is another possible factor. The actual reasons for non-adherence to the STGs need to be further elucidated.

\section{Recommendations}

The findings of this study suggest a few easily implementable actions:

1. Teaching on the importance of standard guideline usage (as opposed to teaching guideline content) during orientation training for staff, to ensure that all doctors irrespective of rank receive training in the use of STGs and understand the importance of STGs in disease management and prevention in children.

2. The introduction of a standardised clerking sheet to be used by doctors for patients presenting with $\mathrm{DD}$, where all the information required for a successful consultation, as described in the STGs, is presented.

3. Regular record and clinical audit of patients presenting with DD to assess if guidelines are being adhered to and, if not, to assess the impact of this on morbidity and mortality.
4. Action plans based on audit results can lead to further strategies for improving quality of care for children with DD.

The global target set for MDG 4 was to reduce U5 MR by twothirds between 1990 and 2015. According to the MDG Report 2015, the global U5 MR has declined by more than half, with the rate of reduction of U5 MR more than tripling since the early 1990s. ${ }^{[10]}$ In sub-Saharan Africa, the annual rate of reduction of U5 MR was over five times faster during 2005 - 2013 than during 1990 - 1995. Despite impressive improvements in most regions, current trends are not yet sufficient to meet the MDG 4 target. At today's rate of progress, it would take about 10 more years to reach the target. ${ }^{[1]}$

DD is a significant cause of childhood mortality in SA and more work needs to be done to limit unnecessary loss of life caused by this preventable illness. This study focused on one aspect of care by assessing if doctors adhered to STGs for the management of DD.

\section{Conclusion}

This study has identified that the majority of doctors at EDH POPD did not follow STGs in the management of children with acute DD. Solutions to the problem are broader than simply issuing instructions on guideline usage to junior doctors. As described in a recent article in The Lancet '... if a health system is weak, guidelines cannot compensate for it. Addressing issues in quality of care and supporting health systems is necessary to tackle the challenges of paediatric care in resource limited settings. ${ }^{[11]}$

\section{References}

1. World Health Organization. Children: Reducing Mortality Factsheet No. 178 Geneva: WHO, 2012. http://www.who.int $>$ factsheets $>$ fs 178 (accessed 14 April 2016).

2. Kerber KJ, Lawn JE, Johnson LF, et al. South African child deaths 1990 - 2011: Have HIV services reversed the trend enough to meet Millennium Development Goal 4? AIDS 2013;27(16):2637-2648. http://dx.doi.org/10.1097/01. aids.0000432987.53271.40

3. Sanders D, Bradshaw D, Ngongo N. The status of child health in South Africa In: Kibel M, Lake L, Pendelbury S, Smith C, eds. South African Child Gauge 2009/2010. Cape Town: Children's Institute, University of Cape Town; 2010:31.

4. Westwood A. Diarrhoeal Disease. In: Stephen CR, Bamford LJ, Patrick ME, Wittenberg DF, eds. Saving Children 2009: Five Years of Data. A Sixth Survey of Child Healthcare in South Africa. Pretoria: Tshepesa Press, Medical Research Council, Centers for Disease Control, 2011:61-75.

5. Health statistic indicators. http://indicators.hst.org.za/healthstats/132/data (accessed 2013).

6. World Health Organization (WHO). Declaration of Alma-Ata. International Conference on Primary Health Care, Alma Ata, USSR, 6 - 12 September 1978. http:// www.who.int/publications/almaata_declaration_en.pdf (accessed 14 April 2016).

7. Quick JD. Essential medicines twenty-five years on: Closing the access gap. Health Policy Plan 2003;15(1):1-3. http://dx.doi.org/10.1093/heapol/18.1.1

8. Sooruth UR, Sibiya MN, Sokhela DG. The use of Standard Treatment Guidelines and Essential Medicines List by professional nurses at primary healthcare clinics in the uMgungundlovu District in South Africa. Int J Afr Nurs Sciences 2015;(3):50-55. http://dx.doi.org/10.1016/j.ijans.2015.08.001

9. Statistics South Africa. Mortality and Causes of Death in South Africa, 2013: Findings from Death Notification. Pretoria: Statistics South Africa, 2014:33.

10. United Nations. The Millennium Development Goals Report. New York: United Nations, 2015:32-35.

11. Duke T. New WHO guidelines on emergency triage assessment and treatment. Lancet 2016;387(10020):721-724. http://dx.doi.org/10.1016/S01406736(16)00148-3

Accepted 13 July 2016. 
APPENDIX A: CASE REPORT Form

DEMOGRAPHICS

\begin{tabular}{|l|l|l|}
\hline Study no & \multicolumn{2}{|l|}{ DOB } \\
\hline Age & Weight & Height \\
\hline
\end{tabular}

NUTRITIONAL CLASSIFICATION ${ }^{(1)}$

\begin{tabular}{|l|l|l|l|}
\hline NAM & MAM & SAM & Not recorded \\
\hline
\end{tabular}

HIV STATUS

\begin{tabular}{|l|l|l|l|}
\hline Infected & Uninfected & $\begin{array}{l}\text { Uninfected but ongoing } \\
\text { exposure through } \\
\text { breastfeeding }\end{array}$ & Unknown \\
\hline
\end{tabular}

RECEIVED ROTAVIRUS VACCINE ${ }^{(2)}$

\begin{tabular}{|l|l|l|}
\hline Yes & No & Unknown \\
\hline
\end{tabular}

PATIENT CONDITION ${ }^{(3)}$

\begin{tabular}{|l|l|l|l|}
\hline & Yes & No & Unable to \\
\hline Shocked & & & \\
\hline Dehydrated & & & \\
\hline
\end{tabular}

LEVEL OF ATTENDING DOCTOR

\begin{tabular}{|l|l|l|l|l|}
\hline $\begin{array}{l}\text { Paediatric } \\
\text { specialist }\end{array}$ & Medical officer & Registrar & Intern & Unknown \\
\hline
\end{tabular}

STG ADHERENCE

Compliant $=2$, Partially compliant $=1$, Non-compliant $=0$

\begin{tabular}{|c|c|}
\hline \multirow{2}{*}{ Nutritional Classification $^{(4)}$} & Compliance \\
\hline & \\
\hline Shock $^{(5)}$ & \\
\hline Dehydration $^{(6)}$ & \\
\hline Appropriate investigations ${ }^{(7)}$ & \\
\hline Fluid plan correct ${ }^{(8)}$ & \\
\hline Drugs - Zinc & \\
\hline Appropriate antibiotics ${ }^{(9)}$ & \\
\hline Anti-diarrhoeal \& anti-emetics not prescribed & \\
\hline Appropriate place of further care ${ }^{(10)}$ & \\
\hline Caregiver counselled & \\
\hline
\end{tabular}

Notes for completing the Case Report Form

1. The nutritional classification has been done in accordance with the SA NDOH criteria based on the WHO Growth Charts. NAM $=$ No acute malnutrition, MAM = Moderate acute malnutrition, $\mathrm{SAM}=$ Severe acute malnutrition

2. Immunizations recorded as "up to date", will be taken to mean that rotavirus vaccine was given to the child as per recommended schedule and "not up to date" as not given.

3. Assessment of shock and dehydration as made by investigator, on reviewing of records and comparing to the South African Hospital Level STGs and EDL.

4. Whether nutritional status was assessed by doctor

5. Criteria for assessment of shock

Level of consciousness

Capillary refill time

Peripheries (cool or warm)

Pulse

Blood pressure

- Compliant if assessed three or more out of four criteria $($ score $=2$ )

- Partially compliant if assessed two out of four criteria (score =1) 
6. Criteria for assessment of dehydration

Restless or irritable

Eyes / anterior fontanelle

Skin turgor

Ability to drink

- Compliant if assessed three or more out of four criteria $($ score $=2)$

- Partially compliant if assessed two out four criteria $($ score $=1)$

- Non-compliant if no criteria assessed $($ score $=0$ )

7.Investigations

Shock

Severe dehydration

Moderate dehydration

No dehydration

Investigations carried out as per reconds, for assessment of

Arterial blood gas

Bloods

Blood glucose

Urine dipstick

- Compliant if appropriate test chosen as indicated in STGs

- Partially compliant if appropriate and inappropriate tests chosen

- Non-compliant if no tests chosen even though indicated in STGis

8. Fluid management

\begin{tabular}{|c|c|c|c|c|}
\hline $\begin{array}{l}\text { Clinical } \\
\text { condition }\end{array}$ & Shock & Severe Dehydration & Moderate dehydration & Not obviously dehydrated \\
\hline Approach & Needs resuscitation & $\begin{array}{l}\text { Needs urgent fluids and } \\
\text { resuscitation }\end{array}$ & Needs oral rehydration & $\begin{array}{l}\text { Potential dehydration for home } \\
\text { treatment }\end{array}$ \\
\hline
\end{tabular}

- Compliant if appropriate fluid plan chosen for severity assessment, as indicated in STGs

- Partially compliant if appropriate/inappropriate fluid plan chosen as indicated in STGs

- Non-compliant if no fluid plan chosen even though indicated in STGs

9. No antibiotics unless comorbid condition present

10. Place of further care as per patient records

Home: Patient discharged if no visible signs of dehydration

Ward: Patient admitted if shocked, severely dehydrated or moderately dehydrated and not responding to oral rehydration

ORS corner: Patient for a trial of sorol and hydration review after 4 hours.

Unknown

- Compliant if appropriate place of further care chosen for severity assessment, as indicated in STG.

- Partially compliant if inappropriate place of further care chosen as indicated in STG.

- Non-compliant if no further place of care indicated. 